\title{
Reducing rearing cost and increasing survival rate of West Indian sweetpotato weevil, Euscepes postfasciatus (Fairmaire) (Coleoptera: Curculionidae) on artificial larval diet
}

\author{
Yukio SHIMOJI ${ }^{*, \dagger}$ and Masaaki YAMAGISHI ${ }^{\dagger}$ \\ Fruit-Fly Eradication Project Office, Okinawa Prefectural Government; Naha, Okinawa 902-0072, Japan
}

(Received 9 December 2002; Accepted 16 September 2003)

\begin{abstract}
Because the ingredients of the artificial larval diet (the basic diet) used to mass-rear the West Indian sweetpotato weevil Euscepes postfasciatus were expensive, so we substituted materials at $1 / 3$ of the price (the low-cost diet). There was no difference in the survival rate of the weevil between those reared on the basic diet and those on the low-cost diet. As the quantity of artificial diet per rearing tray was increased, the survival rate of the weevil rose significantly up to $30 \mathrm{~g}$ of diet. The survival rate of the weevil was increased 1.6 fold by inoculating eggs in scratching lines $1 \mathrm{~mm}$ deep and $1 \mathrm{~mm}$ wide on the surface of the artificial larval diet. One hundred fifty eggs per rearing tray was probably a reasonable number because the survival rate and the actual number of surviving weevils at 150 eggs did not differ significantly from their respective maximums for other numbers of eggs. Rearing of 45,000 weevils per month was established using these methods. This represents a 4.5 fold increase compared to culturing by the conventional method. The new mass-rearing method could produce 1.6 adult weevils per gram of diet.
\end{abstract}

Key words: Artificial larval diet; reducing rearing cost; increasing survival rate; sweet potato pest; Euscepes postfasciatus

\section{INTRODUCTION}

The West Indian sweetpotato weevil, Euscepes postfasciatus, native to the West Indian Islands, is distributed in some countries of Central and South America and the South Pacific Islands. It is known as a very serious pest of the sweet potato, Ipomoea batatas (L) Lam. (Sherman and Tamashiro, 1954; Raman and Alleyne, 1991). Its distribution has spread rapidly since it was first detected in the Katsuren Peninsula of the Okinawa Main Island (Kohama, 1990), to the Islands of southwestern Japan. These include the Amami Islands, Yoron Island, Okinawa Islands, Miyako Islands and Yaeyama Islands in the Ryukyu Archipelago (Yasuda and Kohama, 1990; Moriya, 1997; Ohmura, 2000). This weevil is specified as an important pest under the Plant Protection Law in Japan. The strict prohibition of movement of fresh sweet potatoes from a pest-infested region to non-infested areas imposes a substantial restriction on the promotion of sweet potato production. In order to have the law revoked, this pest must be eradicated. Application of the sterile insect technique (SIT) is being examined to eradicate this pest in Kume Island located $90 \mathrm{~km}$ to the west of the Okinawa Main Island (Kuba et al., 2000). Establishing a mass-rearing method for the insect is a basic requirement for implementing SIT (Knipling, 1964). Shimoji and Kohama (1996b) developed an artificial larval diet for E. postfasciatus that contains $45.7 \%$ dry weight sweet potato root powder as used in the artificial larval diet developed for the boll weevil, Anthonomus grandis by the USDA (Lindig, 1979). However, the high costs of this diet and the poor survival rate of the weevil make mass rearing difficult. The present study was conducted with the aims of cutting costs and improving performance of the artificial larval diet. Other improvements such as the egg-inoculation method, diet quantity, and the number of eggs per rearing tray were also made to increase the survival rate of the weevil.

\footnotetext{
* To whom correspondence should be addressed at: E-mail: yshimoji@k6.dion.ne.jp

† Present address: Laboratory of Okinawa Forest Ecology, Tsudajuku, 1-3-1 Ohira, Urasoe, Okinawa 901-2113, Japan

* Present address: Research Institute for Subtropics, 1 Kumoji, Naha, Okinawa 900-0029, Japan
} 


\section{MATERIALS AND METHODS}

Experiment (1) Reducing costs of the main ingredients. The primary ingredients of the basic diet developed by Shimoji and Kohama (1996b) (agar, cellulose, protein, sugar, dried yeast, dried sweet potato powder, and distilled water) were replaced with inexpensive ingredients in the low-cost diet as follows (Table 1): Agar (Kanto Chemical Co., Inc.) was replaced with Ina-kanten ${ }^{\circledR}$ foodstuff agar (Ina Foods Industries Inc.); Avicel ${ }^{\circledR}$ cellulose microcrystalline for column-chromatography (MERCK) was replaced with KC FLOCK ${ }^{\circledR}$ as foodstuff cellulose (Nippon Paper Industries); casein (Wako Pure Chemical Industries, Ltd.) was replaced with Esusan-meat ${ }^{\circledR}$ skimmed soybean protein (Ajinomoto Inc.); sucrose (Kanto Chemical Co., Inc.) was replaced with raw sugar (Hokubu Seitoh Inc.); yeast extract (Oriental Yeast Industries) was replaced with AY-65 brewer's yeast (Asahi Beer Brewery); domestic dried sweet potato powder was replaced with Gold mash ${ }^{\circledR}$ sweet potato flake foodstuff (JA Ibusuki); and distilled water was replaced with tap water. The process of Shimoji and Kohama (1996b) was also applied to making the low-cost diet, that is, Ina-kanten ${ }^{\circledR}$ agar was added to tap water and heated to $80^{\circ} \mathrm{C}$. All the ingredients were added to the agar solution while it was allowed to cool to $55^{\circ} \mathrm{C}$. The diet was poured into Petri dishes $(9.0 \mathrm{~cm}$ in diameter, $2.0 \mathrm{~cm}$ in depth) at a rate of $25 \mathrm{~g}$ per dish and allowed to solidify.

Eggs collected using the method of Shimoji and Kohama (1996a) were subjected to surface sterilization with a solution of $70 \%$ ethanol and $5 \%$ formaldehyde (Sugiyama et al., 1998). Five scratch lines were made on the surface of the solid diet. Ten eggs per line, a total of 50 eggs, were inoculated using a tiny brush sterilized with $70 \%$ ethanol. We observed the eclosion of weevils in the pupal chamber made at the bottom of the Petri dish to determine the developmental period from hatching to eclosion. The basic diet was prepared as a control. The experiment was replicated five times at $25^{\circ} \mathrm{C}, 70$ to $80 \% \mathrm{RH}$ under an $\mathrm{L} 14: \mathrm{D} 10$ photoperiod.

Experiment (2) Relationship between the diet quantity and the survival rate. The low-cost diet was placed in five plastic rearing trays $(110 \times 75 \times$ $15 \mathrm{~mm}$ ) in quantities of $10,20,30,40$, and $50 \mathrm{~g}$. The low-cost diet was allowed to solidify and 150 surface-sterilized eggs were then inoculated on the

Table 1. Ingredient cost ratio of the low-cost diet to the basic diet for E. postfasciatus larvae

\begin{tabular}{|c|c|c|c|c|}
\hline Ingredients & Basic $\operatorname{diet}^{\mathrm{a}}(\mathrm{A})$ & Low-cost diet (B) & Quantities $^{\mathrm{b}}$ & Cost ratio $(\mathrm{B} / \mathrm{A})$ \\
\hline Agar & Chemical agar & Ina-kanten ${ }^{\circledR}$ & $4.0 \mathrm{~g}$ & 0.271 \\
\hline Host plant & Dried sweet potato root powder & Gold mash $^{\circledR}$ & $10.0 \mathrm{~g}$ & 0.867 \\
\hline Protein & Casein & Esusan-meat ${ }^{\circledR}$ & $2.4 \mathrm{~g}$ & 0.117 \\
\hline Cellulose & Avicel $^{\circledR}$ & $\mathrm{KC}$ flock ${ }^{\circledR}$ & $1.6 \mathrm{~g}$ & 0.070 \\
\hline Sugar & Sucrose & Raw sugar & $4.0 \mathrm{~g}$ & 0.122 \\
\hline Yeast & Yeast extract & AY-65 brewer's yeast & $1.0 \mathrm{~g}$ & 0.102 \\
\hline Mineral & Salt mixture & Same as basic diet & $0.3 \mathrm{~g}$ & 1.000 \\
\hline Vitamin C & Ascorbic acid & Same as basic diet & $0.2 \mathrm{~g}$ & 1.000 \\
\hline Vitamin B & B-vitamin mixture & Same as basic diet & $5.0 \mathrm{mg}$ & 1.000 \\
\hline Lipogen & Choline chloride & Same as basic diet & $50.0 \mathrm{mg}$ & 1.000 \\
\hline Lipogen & Inositol & Same as basic diet & $40.0 \mathrm{mg}$ & 1.000 \\
\hline Lipogen & Cholesterol & Same as basic diet & $80.0 \mathrm{mg}$ & 1.000 \\
\hline Antibiotics & Potassium sorbate & Same as basic diet & $75.0 \mathrm{mg}$ & 1.000 \\
\hline Antibiotics & Methyl $p$-hydroxybenzoate & Same as basic diet & $75.0 \mathrm{mg}$ & 1.000 \\
\hline Solubilizer ${ }^{\mathrm{c}}$ & Ethanol & Same as basic diet & $2.0 \mathrm{ml}$ & 1.000 \\
\hline Water $^{\mathrm{d}}$ & Distilled water & Tap water & $100.0 \mathrm{ml}$ & 1.000 \\
\hline Total ratio & & & & 0.285 \\
\hline
\end{tabular}

\footnotetext{
${ }^{\text {a }}$ Shimoji and Kohama (1996b).

${ }^{\mathrm{b}}$ Quantities of ingredients composing the artificial larval diet.

${ }^{\mathrm{c}}$ Solubilizing cholesterol and methyl $p$-hydroxybenzoate.

${ }^{\mathrm{d}}$ Distilled water and tap water are regarded as about the same cost because it is difficult to calculate those costs.
} 
glassy surface of the diet using a tiny brush. The diet was dissolved 34 days after egg inoculation, and the number of surviving weevils was counted. This experiment was repeated 20 times.

Experiment (3) Inoculating eggs in scratch lines. Ten scratch lines $1 \mathrm{~mm}$ in depth and width were made in the surface of $50 \mathrm{~g}$ low-cost diet in a rearing tray. Ten surface-sterilized eggs per line, a total of 100 eggs, were inoculated using a tiny brush. One hundred eggs were inoculated at random on the glassy surface of the diet as a control. The diet was dissolved 34 days after egg inoculation, and the number of surviving weevils was observed. The experiment was repeated 14 times.

Experiment (4) Relationship between the number of inoculated eggs and the survival rate. Forty grams of the low-cost diet was put into each of six rearing trays. Surface-sterilized eggs were inoculated in the surface of each diet using a tiny brush in quantities of $100,125,150,175,200$, and 250 eggs. The surface of the diet was not scratched. The diet was dissolved 34 days after egg inoculation, and the number of surviving weevils was counted. The experiment was repeated 11 times.

Experiment (5) Mass production. Five hundred polypropylene boxes with polyethylene lids $(26 \times 33 \times 11.5 \mathrm{~cm})$ were prepared as rearing chambers in this procedure. Five hundred adult weevils with the sex ratio of $1: 1$ were put into each of the boxes and fed $600 \mathrm{~g}$ sweet potato roots twice a week. The adults were removed after seven days, and the roots were moved to other rearing boxes of the same size and kept in an environment of $25^{\circ} \mathrm{C}$, $70 \pm 10 \% \mathrm{RH}, 14 \mathrm{~L}: 10 \mathrm{D}$ photoperiod. After seven weeks, approximately 100,000 adults that emerged from the roots were recovered. Fifty polypropylene boxes with a 30 mesh metallic net at the bottom were prepared; these were modified versions of the egg collecting device of Shimoji and Kohama (1996a), i.e. new egg collection devices $(16 \times 22.5 \times 8 \mathrm{~cm})$, and 2,000 adults (the sex ratio of $1: 1)$ were set in each box. Approximately 100,000 eggs were then collected per week using the egg collection method of Shimoji and Kohama (1996a). These collected eggs were surface-sterilized and put into a test tube $(10 \mathrm{~mm}$ dia., $90 \mathrm{~mm}$ long), capped with a 30 mesh lid. The test tube was turned upside down and shaken over the whole surface of the diet in the plastic rearing trays. Thus, the eggs were planted by being sprinkled through the mesh lid (hereafter referred to as the sprinkling method). The procedure was repeated every week.

The rearing trays planted with eggs were kept under conditions of $25^{\circ} \mathrm{C}, 70 \pm 10 \% \mathrm{RH}$ for seven weeks. The number of adults produced each week was summarized monthly and compared with that of the conventional rearing method. We will henceforth refer to the conventional method as "before modification" and the improved method as "after modification." A comparison was made between six months preceding the modification and six months following the modification.

Before modification: An average of 500 eggs (range 200 to 1,000 eggs) per plastic rearing tray were inoculated on the glassy surface of the lowcost diet setting the diet quantity at $100 \mathrm{~g}$, and using the sprinkling method.

After modification: The low-cost diet was set at 30 to $40 \mathrm{~g}$. The whole surface of the diet was then lightly scratched using a $50 \mathrm{~mm}$ long and $10 \mathrm{~mm}$ wide saw blade before planting the eggs. Finally, about 150 eggs were sprinkled over the diet.

Statistical analysis. Mann-Whitney's $U$-test was used to compare the results of experiments (1) and (3). Analysis of variance with Scheffe's test was used to assess the relationship among the values of the result in experiments (2) and (4). In the above values, the hatchability and the survival rate among the inoculated eggs were transformed to arcsine square-root before statistical analysis.

\section{RESULTS}

\section{Experiment (1) Reducing costs of main ingredi- ents}

Table 2 shows results of the tests. Significantly more adults emerged from the low-cost diet than from the basic diet. The number of hatches for the two diets did not differ significantly. In addition, the developmental period from hatching to eclosion was significantly shorter for the low-cost diet than for the basic diet. These results indicate that the low-cost diet is superior to the basic diet in rearing. The cost of ingredients was reduced to about one-third of the cost of the basic diet (Table $1)$. 
Table 2. Development of E. postfasciatus on the low-cost diet and the basic diet at $25^{\circ} \mathrm{C}, 14 \mathrm{~L}: 10 \mathrm{D}$

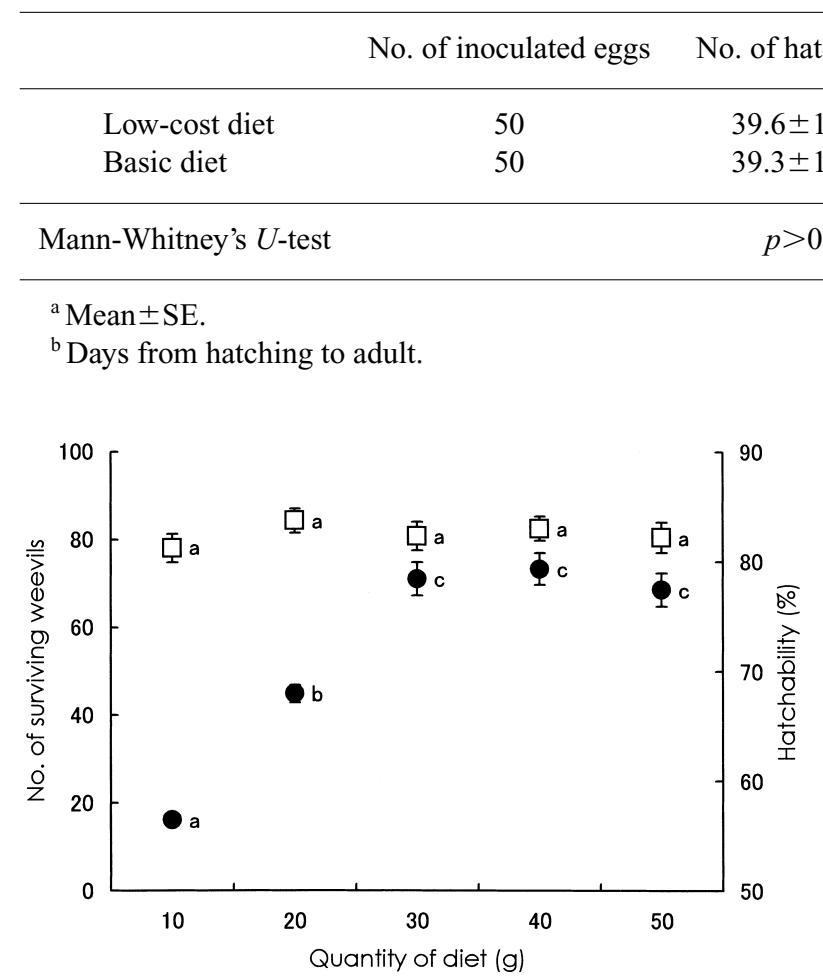

Fig. 1. Number of surviving weevils $(\bullet)$ and hatchabilities $(\square)$ on varied quantities of artificial larval diet of E. postfasciatus. Hatchabilities were transformed to arcsine squareroot before statistical analysis. Means of untransformed data are reported. Means followed by the same letter are not significantly different (analysis of variance followed by Scheffé's test, $p>0.05$ ). Vertical lines show standard errors.

\section{Experiment (2) Relationship between the diet quantity and the survival rate}

Figure 1 shows that there were no significant differences in hatchability using different quantities of diet. However, a diet increase from $10 \mathrm{~g}$ to $30 \mathrm{~g}$ significantly increased (4.4 times) the number of surviving weevils. In addition, there were no significant differences in the number of surviving weevils with a diet increase above $30 \mathrm{~g}$.

\section{Experiment (3) Inoculating eggs in scratch lines}

The number of surviving weevils on the diet with eggs inoculated in scratch lines was $54.6 \pm 2.8$ (mean $\pm \mathrm{SE}, n=14$ ), which was significantly greater than the number $(33.1 \pm 2.8(n=14))$ obtained when eggs were inoculated onto a glassy surface (Table $3)$.
Experiment (4) Relationship between the number of inoculated eggs and the survival rate

The hatchability of inoculated eggs is shown in Fig. 2. There were no significant differences in hatches among the various numbers of inoculated eggs. The number of surviving weevils increased significantly as the number of inoculated eggs increased, however the survival rates significantly decreased (Fig. 3). Consequently, in this experiment, the intersection of the regression curve of the number of developed weevils, $y=12.645 \ln (x)+42.635$ $\left(r^{2}=0.924\right)$ and the regression line of the survival rate, $y=-3.3057 x+47.253\left(r^{2}=0.931\right)$ was at 150 eggs inoculated. Thus, it seems reasonable to inoculate 150 eggs per tray since the number of surviving weevils and the survival rate at 150 eggs do not differ significantly from their respective maximums.

\section{Experiment (5) Mass production}

Rearing the weevils for six months using a modified method based on the outcomes of experiments (2) to (4) resulted in a monthly production that reached around 45,000 weevils, compared to an average of 10,000 weevils before modification (Fig. 4). We converted these to values per gram of diet to compare production efficiency. The average of the monthly production before modification was $0.2 \pm 0.1$ (mean $\pm \mathrm{SD}, n=6)$ weevils per gram. In contrast, the monthly production by the modified method was $1.6 \pm 0.1(n=6)$ weevils, which corresponds to eight times the production of the method before modification. This increase was mainly due to the influence of the diet quantity being reduced from $100 \mathrm{~g}$ to $30 \mathrm{~g}$.

\section{DISCUSSION}

Diet is the most important factor in rearing insects. While the natural diet that the insect con- 
Table 3. The number of surviving weevils on artificial larval diet of E. postfasciatus with eggs inoculated in scratch lines and on glassy surface

\begin{tabular}{ccccc}
\hline Inoculating eggs & No. inoculated eggs & No. hatches ${ }^{\mathrm{a}}$ & No. survived weevils $^{\mathrm{a}}$ & $n$ \\
\hline In scratch lines & 100 & $84.3 \pm 1.4$ & $54.6 \pm 2.8$ & 14 \\
On glassy surface & 100 & $84.3 \pm 1.4$ & $33.1 \pm 2.8$ & 14 \\
\hline Mann-Whitney's $U$-test & & $p>0.05$ & $p<0.01$ \\
\hline
\end{tabular}

${ }^{\mathrm{a}}$ Mean $\pm \mathrm{SE}$.

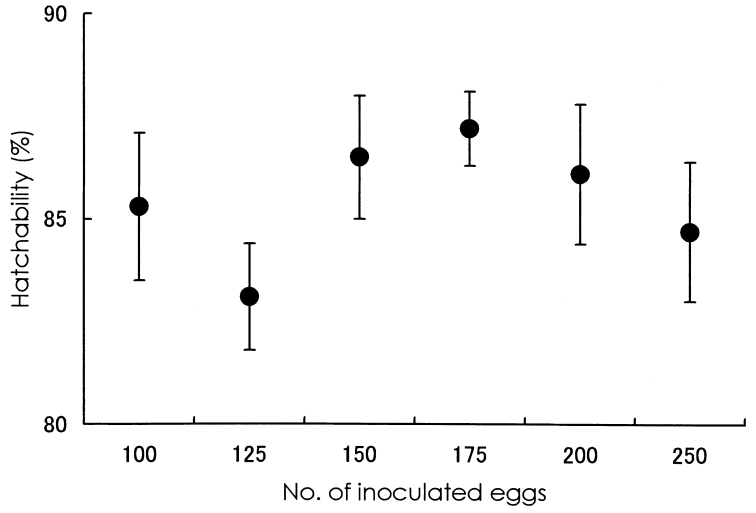

Fig. 2. Hatchabilities on varied number of inoculated eggs. Hatchabilities were transformed to arcsine square-root before statistical analysis. Means of untransformed data are reported. Means are not significantly different (analysis of variance followed by Scheffé's test, $p>0.05$ ). Vertical lines show standard errors.

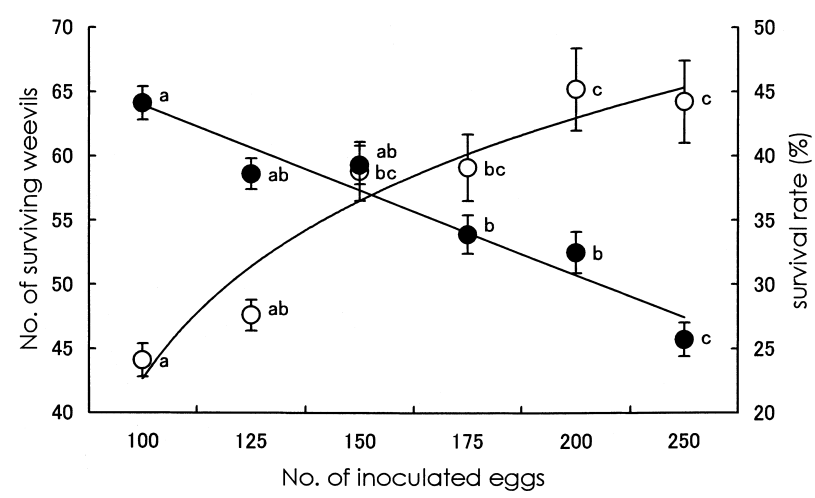

Fig. 3. Relationship between number of inoculated eggs and number of surviving weevils $(\bigcirc)$ or survival rate $(\bullet$ : number of survived weevils per number of inoculated eggs). Survival rates were transformed to arcsine square-root before statistical analysis. Means of untransformed data are reported. Means along the line followed by the same letters are not significantly different (analysis of variance followed by Scheffe's test, $p>0.05$ ). Vertical lines show standard errors.

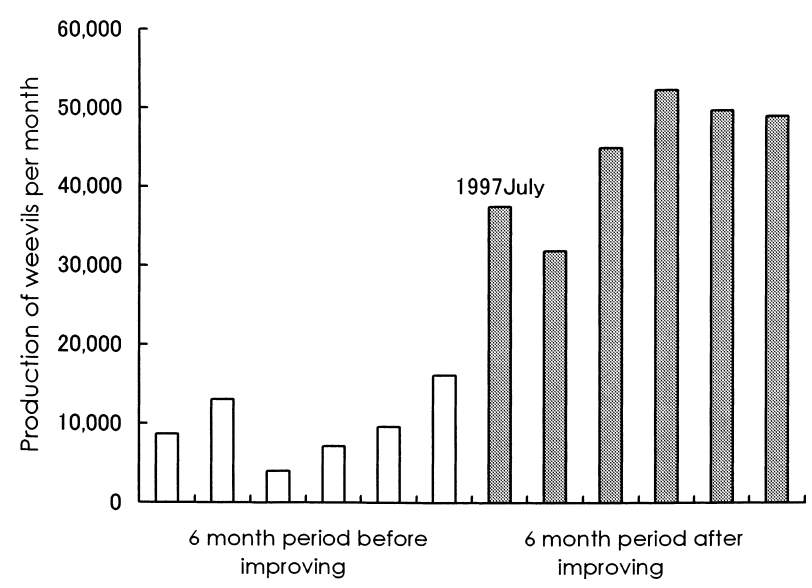

Fig. 4. Changes of the monthly production of weevils over six months before and after improving for rearing methods. The averages of productions "before" and "after" July 1997 were 9,774 $\pm 1,769$ (mean \pm SE) and 44,247 $\pm 3,243$, respectively.

sumes in its natural environment is ideal, it may be difficult to supply throughout the year, and its quality may vary according to seasonal changes. An artificial diet that can be maintained and supplied in a simple manner is desirable for stable mass rearing. For example, an artificial diet with low material costs was developed and produced in a simple manner for the melon fly, which was mass-produced for SIT (Nakamori et al., 1975; Sugimoto, 1978).

Artificial diets have been developed for other weevils, such as the orchid weevil Orchidophilus aterrimus (Mau and Lai, 1988), the pine root collar weevil Hylobius radicis (Hunt et al., 1992), the Pales weevil H. pales (Thomas, 1969; Clark, 1973; Hunt et al., 1992), the root feeding weevil H. transversovittatus (Blossey et al., 2000), the palm weevil Rhynchophorus palmarum (Zagatti et al., 1993), the plum curculio Conotrachelus nenuphar (Yonce et al., 1971), and the white pine weevil Pissodes 
strobi (Zerillo and Odell, 1973; Trudel et al., 1994). The most successful example of artificial mass rearing of weevils is that of the boll weevil (Sikorowski et al., 1983). Lindig (1979) contributed to the success of mass production of the boll weevil by saving time, energy, and labor through the development of an artificial larval diet.

The Okinawa Prefectural Government is planning to implement long-term eradication control of E. postfasciatus by means of SIT. One SIT prerequisite is that mass production of the insect be implemented at a low cost and in a stable quantity (Knipling, 1966). An artificial larval diet for $E$. postfasciatus has been developed (Shimoji and Kohama, 1996b), but at high material costs.

We succeeded in improving the number of surviving weevils per gram of diet by eight fold and in reducing the costs of diet materials to $30 \%$ from that of the conventional rearing method. Therefore, production of $1,000,000$ weevils per week was achieved at a material cost of 187,500 yen.

The measures taken in this experiment to improve the production of $E$. postfasciatus on an artificial larval diet included the results of experiments (2) determining the quantity of diet per rearing tray (3) confirming the effects of scratching the surface of the diet on the survival of eggs, and (4) determining the number of inoculated eggs per rearing tray.

In conclusion, the rearing method for E. postfasciatus in this experiment using an improved artificial diet successfully reduced the material costs and improved the survival rate compared with the unimproved rearing method. An additional direction of this study for E. postfasciatus will be to further reduce the rearing costs without reducing their life history traits, such as fecundity and longevity, during continued mass-rearing.

\section{ACKNOWLEDGEMENTS}

We thank Dr. S. Moriya (Insect Ecology Laboratory, National Agricultural Research Center) for critical reading of the original manuscript. We also thank Dr. T. Miyatake (Faculty of Agriculture, Okayama University) for his valuable discussion and helpful comments.

\section{REFERENCES}

Blossey, B., D. Eberts, E. Morrison and T. R. Hunt (2000) Mass rearing the weevil Hylobius transversovittatus (Coleoptera: Curculionidae), biological control agent of Lythrum salicaria, on semiartificial diet. J. Econ. Ento- mol. 93: 1644-1656.

Clark, E. W. (1973) Hylobius pales: a meridic larval diet using sitosterol. J. Econ. Entomol. 66: 841-843.

Hunt, D. W. A., G. Lintereur and K. F. Raffa (1992) Rearing method for Hylobius radicis and $H$. pales (Coleoptera: Curculionidae). J. Econ. Entomol. 85: 1873-1877.

Knipling, E. F. (1964) The potential role of the sterility method for insect population control with special reference to combining this method with conventional methods. USDA-ARS 33-98: 1-54.

Knipling, E. F. (1966) Introduction. In Insect Colonization and Mass Production (C. N. Smith ed.). Academic Press, New York, pp. 2-12.

Kohama, T. (1990) Invasion and colonization of the sweet potato weevils in Okinawa and current problems for their control. Plant Protect. 44: 115-117 (in Japanese).

Kuba, H., T. Teruya and M. Sakakibara (2000) The significance of eradication of sweetpotato weevil and small sweetpotato weevil, and the development of eradication project for these weevils. Plant Protect. 54: 483-486 (in Japanese).

Lindig, O. H. (1979) A replacement for cottonseed meal and meats in boll weevil diets. J. Econ. Entomol. 72: 291-292.

Mau, R. F. L. and P. Lai (1988) Evaluation two formulations of a laboratory diet for the orchid weevil, Orchidophilus aterrimus (Waterhouse). Proc. Hawaii Entomol. Soc. 28: $205-211$

Moriya, S. (1997) Is it possible to eradicate the two weevil pests of sweet potato, Cylas formicarius and Euscepes postfasciatus from Japan? Bull. Okinawa Agric. Exp. Stn. 18: 19-27.

Nakamori, H., H. Kakinohana and H. Soemori (1975) Mass rearing of the melon fly, Dacus cucurbitae Coquilett. I. Effect of rearing density on the yield and quantity of flies. J. Okinawa Agric. 13: 27-32 (in Japanese).

Ohmura, K. (2000) The significance of eradication of sweetpotato weevil and small sweetpotato weevil, and the development of eradication project for these weevils. Plant Protect. 54: 443 (in Japanese).

Raman, K. V. and E. H. Alleyne (1991) Biology and management of the West Indian sweet potato weevil, Euscepes postfasciatus. In Sweet Potato Pest Management, A Global Perspective (R. K. Jansson and K. V. Raman eds.). Westview Press, Boulder, pp. 263-281.

Sherman, M. and M. Tamashiro (1954) The sweetpotato weevils in Hawaii: Their biology and control. Hawaii Agric. Exp. Stn. Tech. Bull. 23: 1-36.

Shimoji, Y. and T. Kohama (1996a) A simple method for collecting eggs of the West Indian sweet potato weevil, Euscepes postfasciatus (Fairmaire) (Coleoptera: Curculionidae). Appl. Entomol. Zool. 31:37-42.

Shimoji, Y. and T. Kohama (1996b) An artificial larval diet for the West Indian sweet potato weevil, Euscepes postfasciatus (Fairmaire) (Coleoptera: Curculionidae). Appl. Entomol. Zool. 31: 152-154.

Sikorowski, P. P., J. G. Griffin, J. Roberson and O. H. Lindig (1983) Boll Weevil Mass Rearing Technology. University Press of Mississippi, Jackson. 172 pp. 
Sugimoto, A. (1978) Mass rearing of larvae of the melon fly, Dacus cucurbitae Coquillett (Diptera: Tephritidae). Jpn. J. Appl. Entomol. Zool. 22: 219-227.

Sugiyama, M., Y. Shimoji and T. Kohama (1998) Marking of the West Indian sweetpotato weevil, Euscepes postfasciatus (Fairmaire) (Coleoptera: Curculionidae) with Calco Oil Red dye II. Effects of the dye on fecundity, longevity and sexual maturity. Appl. Entomol. Zool. 33: 375-378.

Thomas, H. A. (1969) A meridic diet and rearing technique for the pales weevil larva. J. Econ. Entomol. 62: 1491-1494.

Trudel, R., R. Lavallee, E. Bauce and J. Cabana (1994) Variations in ground white pine bark concentration in artificial diet in relation to egg laying, feeding, and mortality of Pissodes strobi (Coleoptera: Curculionidae). J. Econ.
Entomol. 87: 96-100.

Yasuda, K. and K. Kohama (1990) Distribution of the sweetpotato weevil, Cylas formicarius (Fabricius) and West Indian sweetpotato weevil, Euscepes postfasciatus (Fairmaire) in Okinawa Prefecture. Proc. Assoc. Plant Prot. Kyushu 36: 123-125 (in Japanese).

Yonce, C. E., C. R. Gentry and R. R. Pate (1971) Artificial diet for rearing larvae of the Plum curculio. J. Econ. Entomol. 64: 1111-1113.

Zagatti, D. R., A. Berthier and L. Nadarajan (1993) Continuous rearing of the palm weevil, Rhynchophorus palmarum (L.), in the laboratory. Oleagineux 48: 213-217.

Zerillo, R. T. and T. M. Odell (1973) White pine weevil: a rearing procedure and artificial medium. J. Econ. Entomol. 66: 593-594. 